\title{
Proceso constructivo del Rockódromo Arena de Madrid, España
}

\author{
Constructive proccess of Rockodromo Arena \\ of Madrid, Spain
}

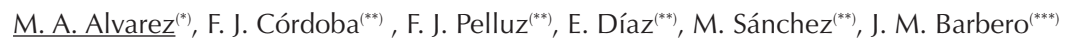 \\ RESUMEN \\ SUMMARY
}

Este proyecto parte de la necesidad de consolidar el recinto del Rockódromo de la Casa de Campo de Madrid mediante la construcción de un Pabellón Arena, un Pabellón auxiliar y un Túnel de conexión. El propósito de la obra consiste en la posibilidad de albergar en el Pabellón unos usos múltiples que permitan su funcionamiento como lugar de espectáculos, con una capacidad de 10.800 asientos, así como de usos feriales.

Se ha proyectado una cubierta como el elemento más identificador, con una tipología de "rueda de bicicleta", para cubrir el Pabellón Arena, que debido a su diafanidad y versatilidad puede ser capaz de suministrar la luz que requieren este tipo de edificios.

146-106

Palabras clave: arquitectura multiusos, arquitectura versátil, cubierta, prefabricación, pretensado, muro-cortina, estructura especial.

\section{INTRODUCCIÓN}

El espacio del proyecto se localiza en la Casa de Campo, lugar histórico enraizado y ligado al devenir de la villa de Madrid, como pulmón, y espacio ecológico, paisajístico y lúdico.

Finca real en un principio, y ligada a la monarquía hasta la instauración de la Segunda Republica, que la declara Parque Histórico, con el objeto de que se convierta en un espacio de ocio, cultura y esparcimiento. Este planteamiento queda truncado por el estallido de la Guerra Civil.

Durante la Dictadura se construye en su interior la Feria del Campo, exaltación de los valores, arquitectura, folclore y costum-
It has understand this project as a need to repair the Rockodromo place located in Casa de Campo of Madrid by means of the construction of Arena pavilion, an auxiliary pavilion and a connection tunnel. The aim is the possibility of contain multiple uses, as spectacle use with a total capacity of 10.800 seat spectators, a fair use.

It has projected a roof with a "bicycle wheel typology" for covering the Arena Pavilion as the most identify element. This roof will is able to provide the light that needs this building types.

Keywords: multi-use architecture, versatile architecture, roof, prefabrication, prestressed, curtain wall, spetial structure.

bres tradicionales de las diversas regiones de España, como escaparate de la ideología y logros del régimen.

Posteriormente y por parte del Ayuntamiento de Madrid se retoma la idea de la Casa de Campo como contenedor de lugares de recreo, pero contrariamente al concepto republicano, no de iniciativa pública sino privada.

El parque de la Casa de Campo se definió en el plan General de Ordenación Urbana de 1985 como "Parque urbano que mantendrá una primacía de la zona forestada sobre la acondicionada mediante urbanización" dividiéndolo en dos zonas: parque Urbano, que abarca la zona de equipamientos y Parque Suburbano.

\footnotetext{
(*) Universidad Politécnica de Madrid (Madrid, España)

${ }^{(* *)}$ FCC (Madrid, España)

${ }^{(* * *)}$ Ministerio Administraciones Públicas (Madrid, España) 
El Plan General de Ordenación Urbana de Madrid de 1997 delimita para la zona del "Rockódromo", dentro del área de Ordenación específica ACE 00.04 "Feria del Campo", un uso característico de Dotacional de Servicios Colectivos a desarrollar mediante un Plan Especial por Iniciativa Publica, se definen objetivos y establece condiciones para su concepción y desarrollo.

La situación urbanística actual demanda la consolidación de este recinto como contenedor de actividades, dentro del respeto al entorno paisajístico, eludiendo la incomunicación y compartimentación, derivados del tipo de desarrollo urbano del municipio, sectorial, discontinuo y afuncional en lo que al lugar y entorno se refiere. Incentivando y desarrollando interconexiones naturales integradas en el entorno, reduciendo al mínimo lo urbano o integrándolo en el marco.

Los criterios de intervención se especifican en el artículo 32 de la Ley de Patrimonio, cuyo artículo 35 establece la necesidad de supervisión de los proyectos a ejecutar en los Bienes de Interés Cultural por los Servicios Técnicos de la Dirección General de Patrimonio Cultural de la Comunidad de Madrid.

El nuevo equipamiento se completó en su momento, la obra finalizó en octubre de 2005, la oferta de la ciudad como apoyo de cara a la candidatura olímpica madrileña,
Esta circunstancia se renueva ahora con la reactivación de dicha candidatura para una fecha posterior, que podrá utilizarlo, dada su versatilidad, para distintas modalidades deportivas.

\section{SITUACIÓN Y EMPLAZAMIENTO}

El Rockódromo Arena, cuyo nombre conjuga una antigua instalación del mismo ámbito con una reminiscencia clásica-graderío abierto al aire libre del mismo nombre, sobre el que se asienta, que ocupaba a su vez el antiguo espacio de exposiciones ganaderas de la Feria del Campo, con la referencia a los antiguos anfiteatros también para usos-espectáculos múltiples y diversos, esta situado en los recintos feriales que la Empresa Municipal Campo de las Naciones tiene en la Casa de Campo de Madrid (Figura 1).

Está constituido por un Pabellón de usos múltiples con una capacidad para 10.800 asientos, Ilamado Pabellón Arena, con una superficie construida $29.800 \mathrm{~m}^{2}$, un Pabellón Auxiliar parcialmente enterrado en una ladera con una superficie construida de $4.000 \mathrm{~m}^{2} \mathrm{y}$ un Túnel de Conexión entre sus componentes y otros edificios preexistentes, el Pabellón de la Pipa y el de Cristal (edificio protegido y catalogado) en esa voluntad de intercomunicación antes mencionada.

Se ha construido además un tercer edificio de instalaciones enterrado y alejado $250 \mathrm{~m}$ del

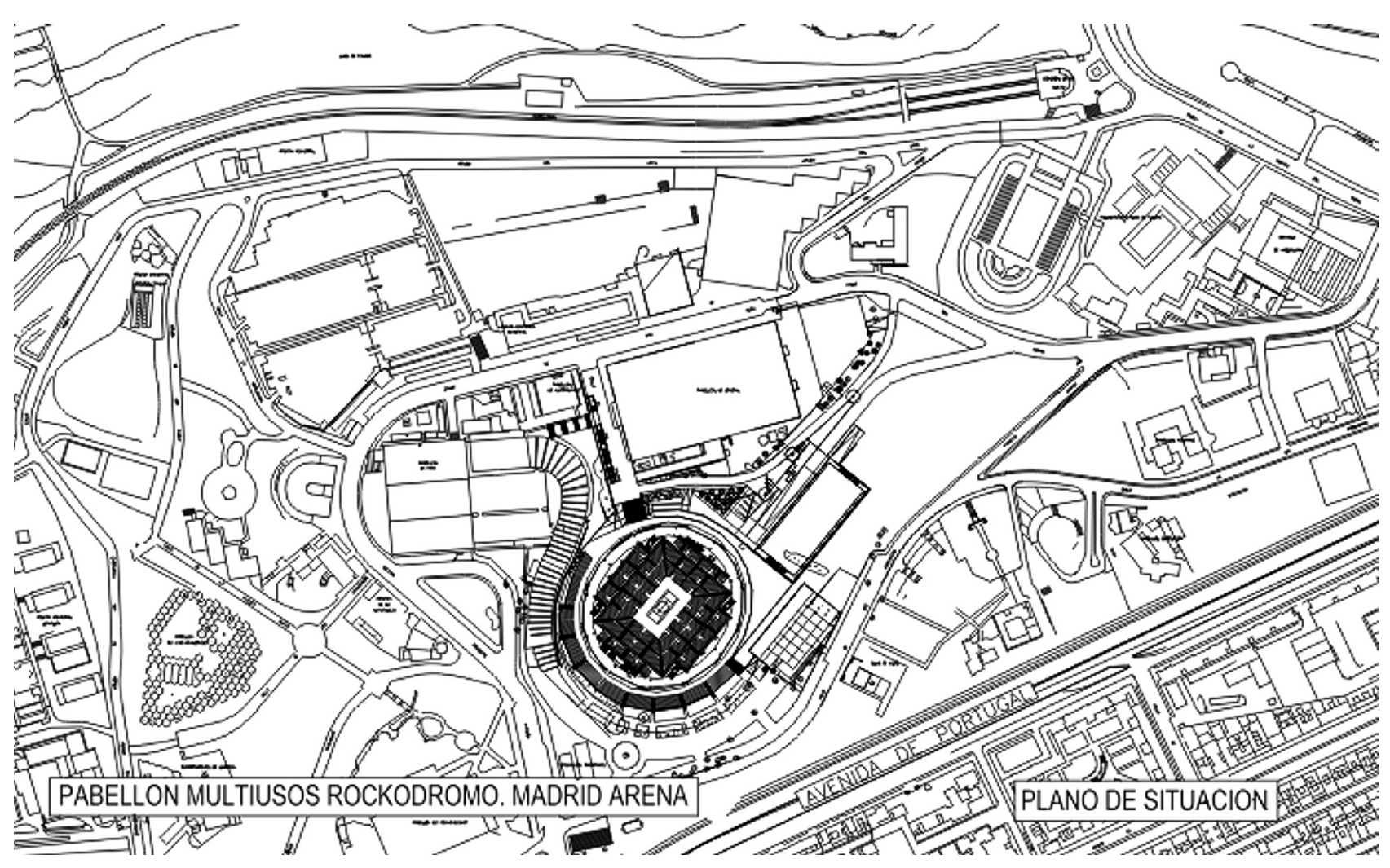



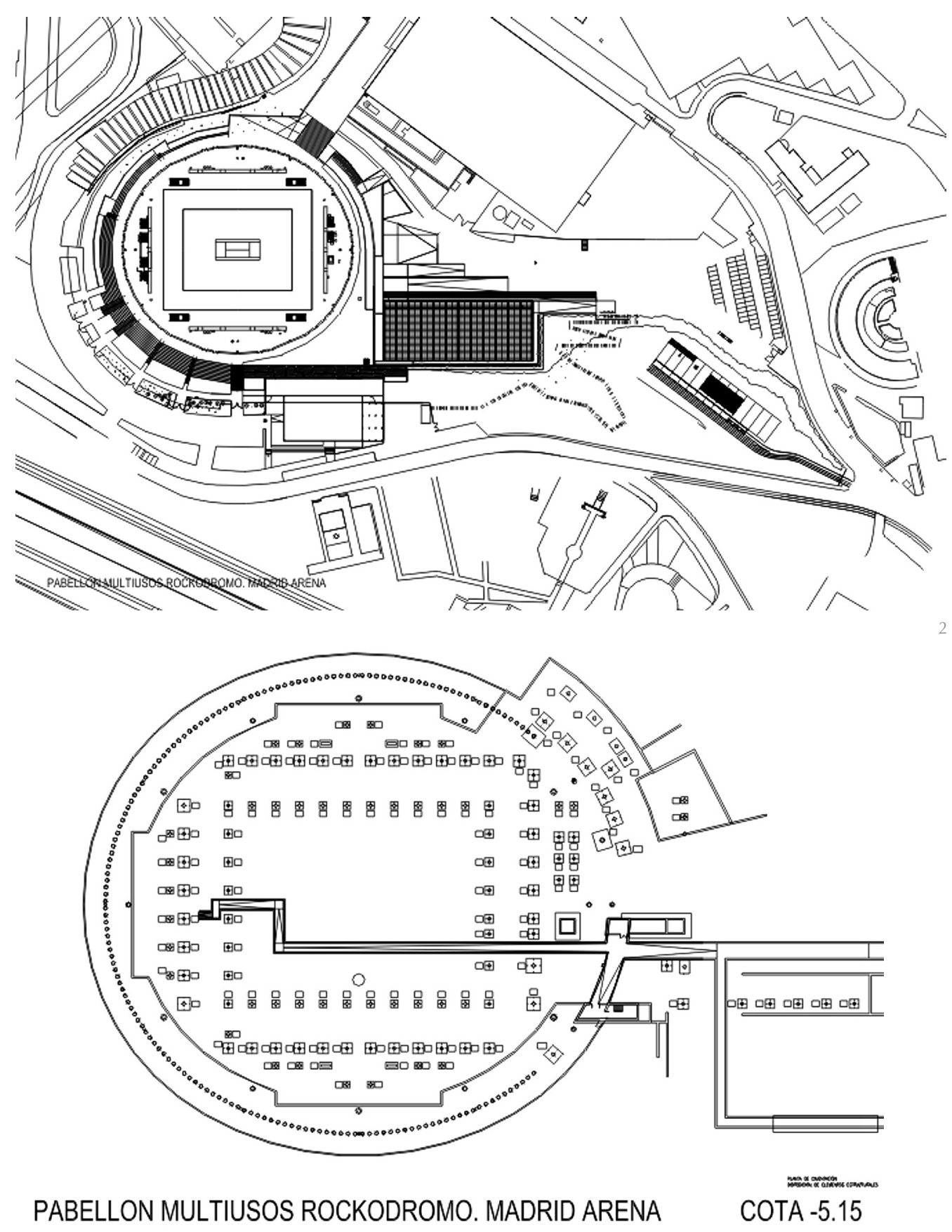

pabellón del Rockódromo, para la generación y transformación de la energía demandada por los distintos servicios del complejo, que cuenta con $1.250 \mathrm{~m}^{2}$ construidos. Su conexión con los otros pabellones se realiza con una galería enterrada visitable como se puede ver en la Figura 2.

\section{DESCRIPCIÓN ARQUITECTONICA}

\subsection{Pabellón Arena}

El edificio se proyectó de planta ovoidal y parcialmente enterrado en su fachada suroeste, a fin de adaptarse a la orografía de la antigua vaguada sobre la que está construido, siguiendo así en ambos aspectos los modelos clásicos grecolatinos para este tipo de uso y edificación. Se libera hacia el noreste, formando una fachada en la que el alzado se manifiesta totalmente exento.

El proyecto sufrió una modificación durante la ejecución de las obras. El motivo fue la cota de la cubierta, que no se quiso rebajar hasta nivel señalado en el proyecto, eligiéndose una superior a ella. Con el fin de que esta modificación de cota no variara las dimensiones-volumen del pabellón, no se excavó-vació hasta la cota definitiva, sino una intermedia.

El Pabellón consta de tres plantas (Figuras 3-5), la de solera y dos plantas conforma-
2. Planta de los edificios. 3. Planta de Cota $-5,15$. 
4. Planta de Cota $+0,00$.

5. Planta de Cota $+5,00$.

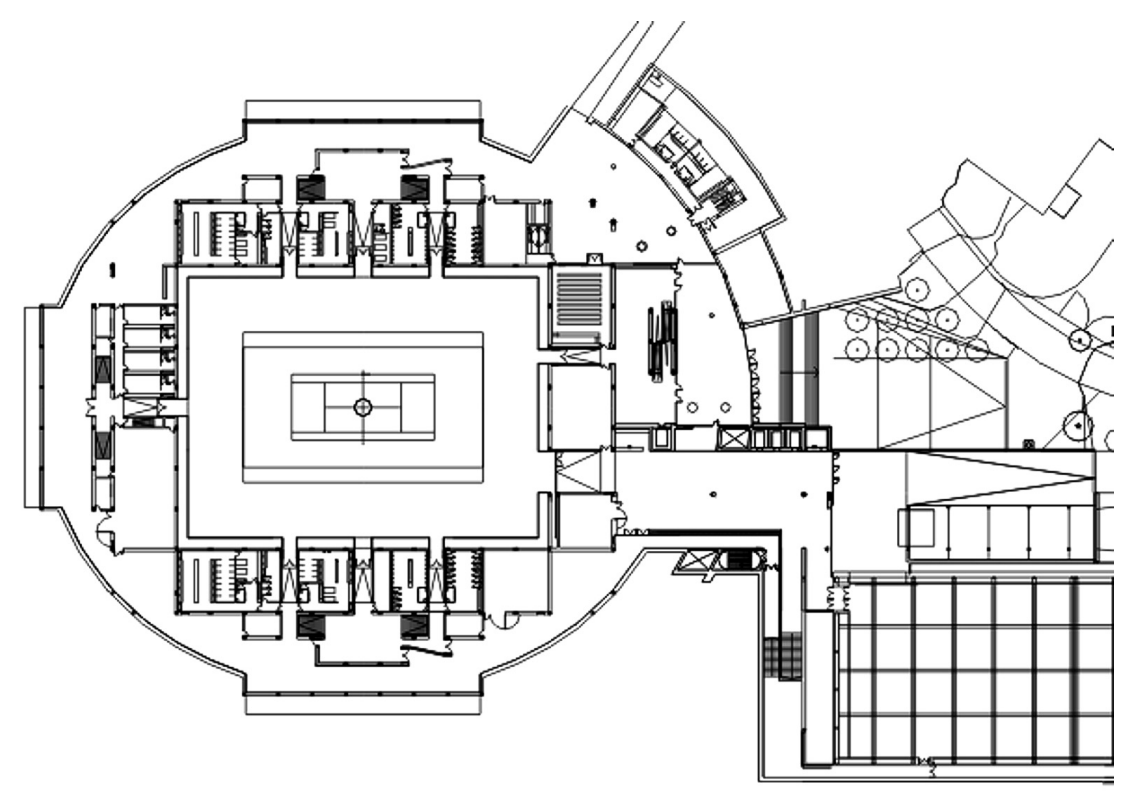

PABELLON MULTIUSOS ROCKODROMO. MADRID ARENA

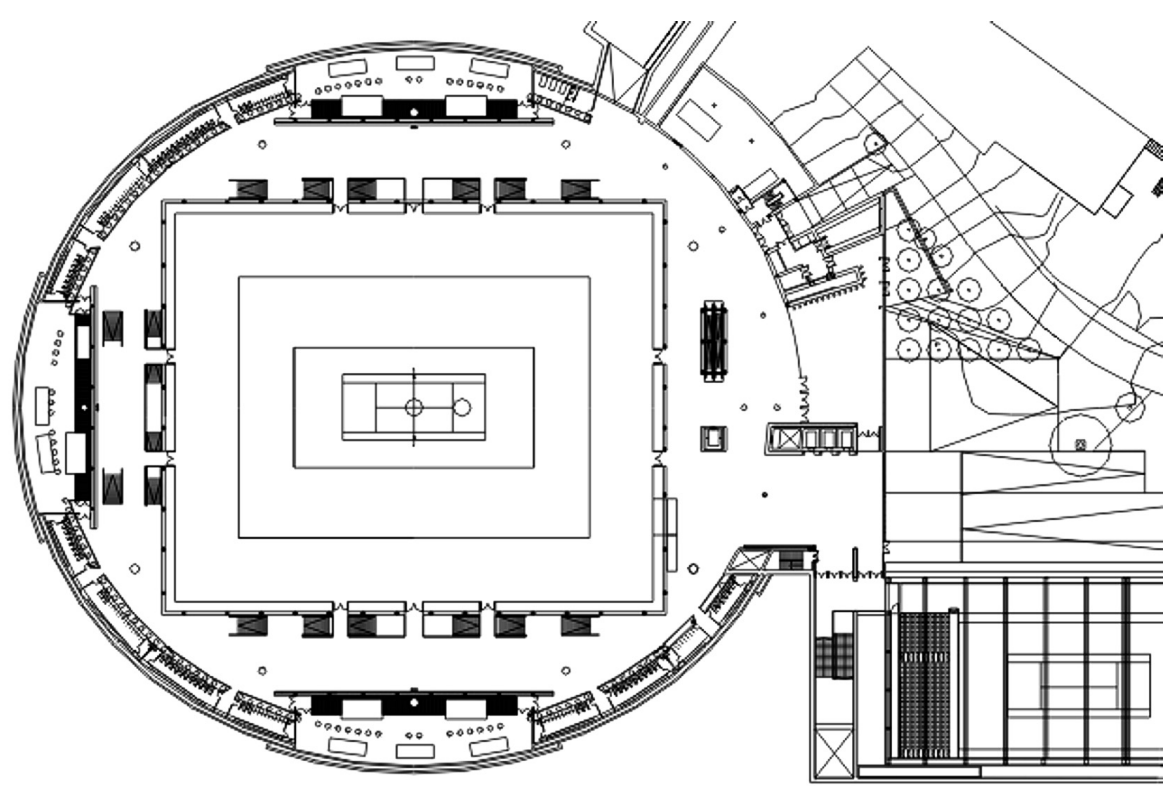

PABELLON MULTIUSOS ROCKODROMO. MADRID ARENA

COTA +5.00

das por un conjunto estructural prefabricado interior de $14.100 \mathrm{~m}^{2}$ con una sobrecarga de uso de $1.500 \mathrm{Kg} . / \mathrm{m}^{2}$ que permitirá en los usos de feria la circulación de camiones sobre la estructura. En la figura 6 se muestran las secciones del edificio.

La Fachada noreste, donde está situado el Lobby del edificio junto al restaurante y jardines interiores (Figura 7), se realizó mediante una estructura in situ de hormigón visto con una superficie de $3.750 \mathrm{~m}^{2}$ y un muro cortina de doble pared de vidrio STADIP con estructura metálica interna vista e iluminación interior.
La Cubierta, como en todo este tipo de edificios, en los que se requiere gran luz, diafanidad y versatilidad, es el elemento más característico e identificador, siendo además estructuralmente singular, con una tipología de "rueda de bicicleta". Esta formada por una estructura mixta con un anillo exterior de hormigón armado apoyado en su directriz, con luces de 30 m y una esbeltez de 1/30 de la luz, en doce pares de pilares que se encuentran pilotados hasta atravesar el terreno aluvial de la vaguada y se empotran en el estrato competente. En dicho anillo de hormigón se apoyan seis vigas armadas metálicas que convergen en un anillo central de acero, (Figura 8, pág. 


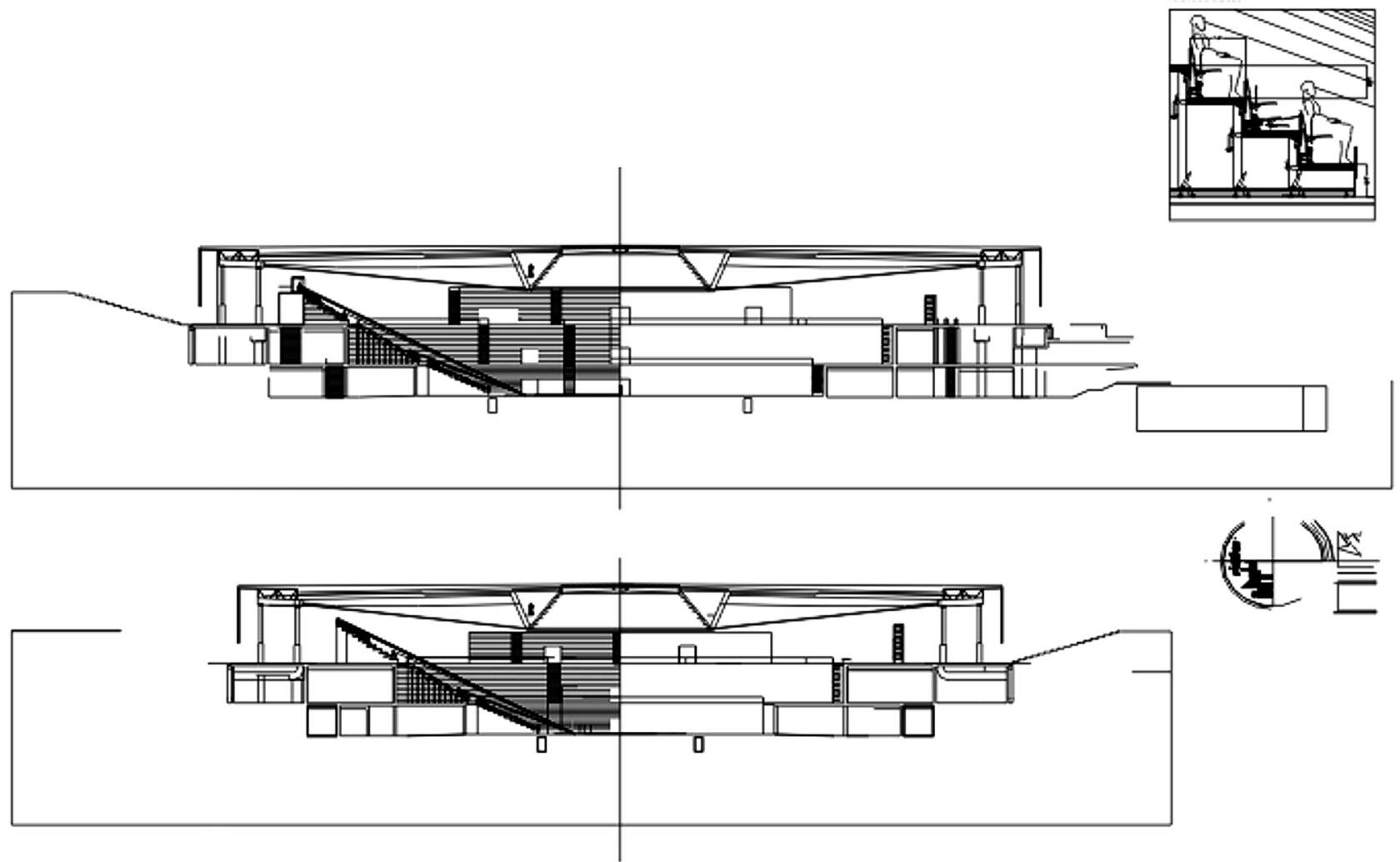

PABELLON MULTIUSOS ROCKODROMO. MADRID ARENA

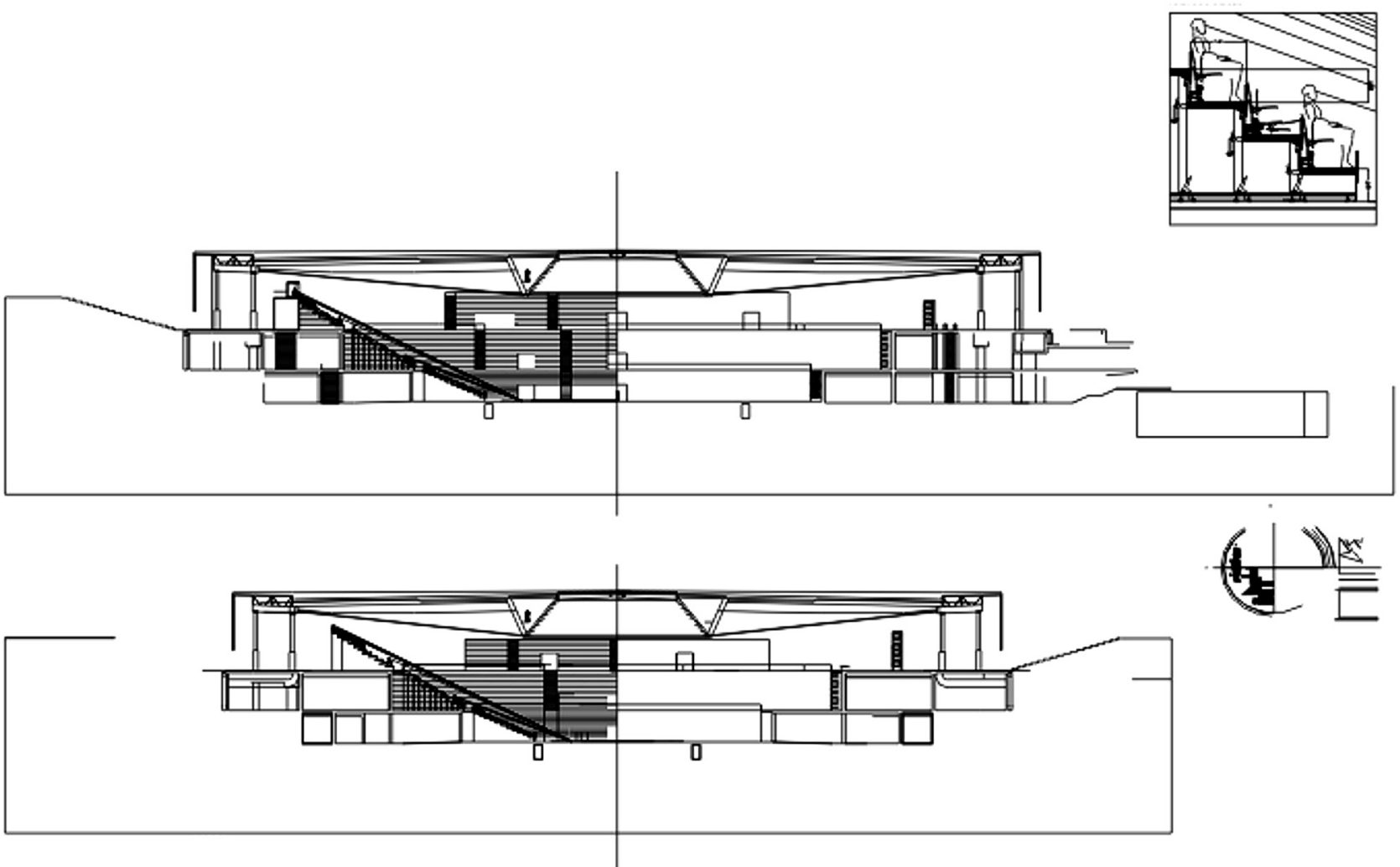

\section{PABELLONMULTIUSOSROCKODROMO. MADRIDARENA}

SECCIONES

10) dicho anillo se halla sustentado por seis tirantes postesados anclados a éste y al anillo exterior que traccionan y comprimen a ambos respectivamente. De esta manera se obtiene una cubrición de aspecto plano, con la que se consigue una luz libre de $125 \mathrm{~m}$. Un entramado de barras cilíndricas de acero unidas por esferas de fundición formalizando tetraedros apoyadas sobre las seis vigas definen la estructura espacial que conforma el entrevigado sobre la que se apoya una cubierta tipo DECK. La cubierta cuenta con 188 puntos de los que se puede cargar una tonelada de peso, lo que permite múltiples posibilidades escénicas. También cuenta con 144 ventanas y un lucernario central que puede abrirse a la luz natural (Figura 9, pág. siguiente). Los Recintos interiores, independientes de la estructura de la cubierta, se construyen con muros de hormigón realizados a dos caras. Sobre estos muros y un conjunto de pilares prefabricados se apoya una estructura también prefabricada formada por vigas de hormigón pretensado con luces medias entre 8 y $12 \mathrm{~m}$. Sobre ellas se colocan unas placas alveolares con capa de compresión de hormigón in situ. Las Particiones, se realizan en bloque de hormigón enfoscado posteriormente y revestido, en función de la nobleza de las estancias que configuran, de distintos materiales: tableros de partículas de madera orientadas OSB, aluminio ó metacrilato retroiluminado.
Los Pavimentos, son de hormigón pulido con planeidad estándar en las zonas comunes y de alta planeidad $(2 \mathrm{~mm} / \mathrm{m})$ en las zonas de graderío. Las Gradas, formadas por 10.800 asientos plegables son retráctiles (Figura 10, pág. 11), con una motorización que las recoge quedando reducidas a un frente de un metro en cada nivel, liberando tres pasillos.

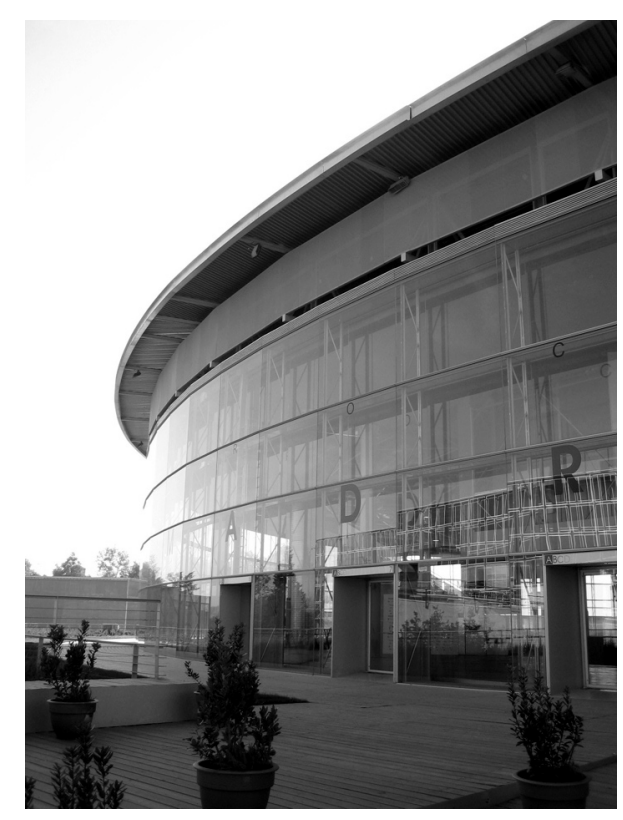



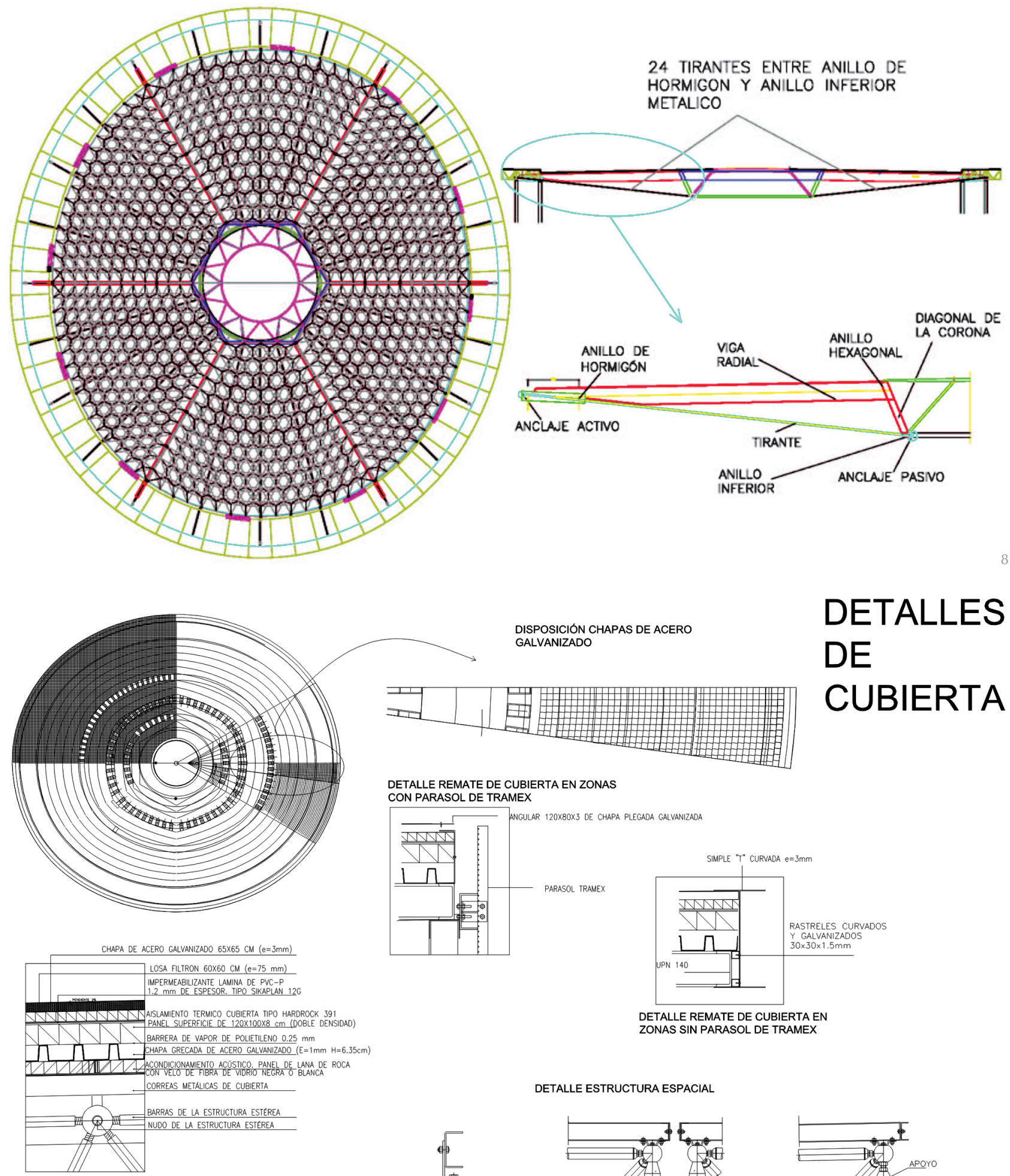

SECCION TIPO DE CUBIERTA

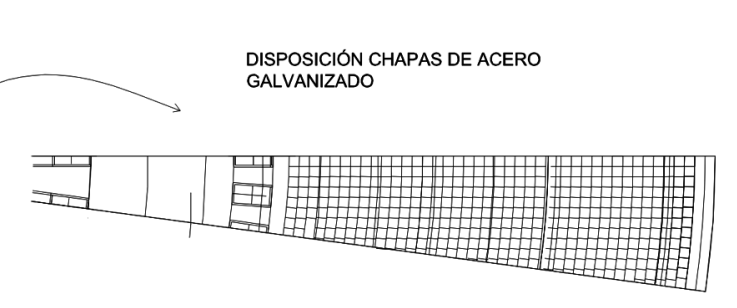

DETALLES

DE CUBIERTA DETALLE REMATE DE CUBIERTA EN ZONAS CON PARASOL DE TRAMEX

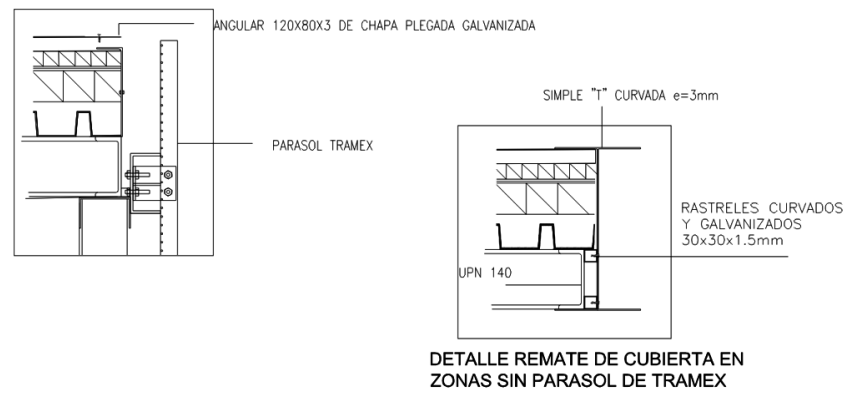

DETALLE ESTRUCTURA ESPACIAL
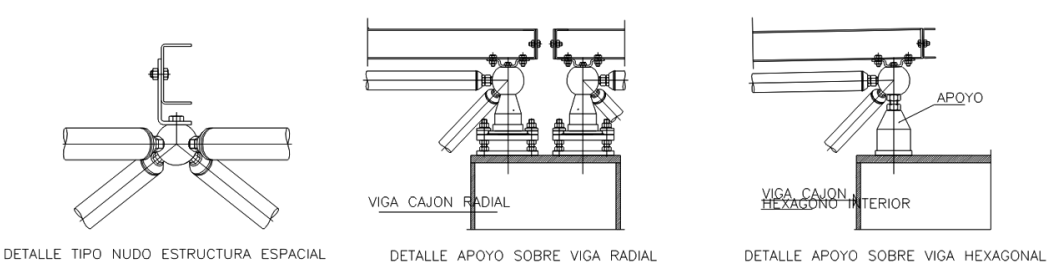

PABELLON MULTIUSOS ROCKODROMO. MADRID ARENA

8. Planta y sección de la cubierta.

9. Detalles de la cubierta.
Se encuentran apoyadas en la estructura prefabricada de hormigón. La motorización al liberar unas superficies de $6.000 \mathrm{~m}^{2}$ permite la versatilidad que se necesita para ser un pabellón arena y que posibilita los usos de ferias en este recinto
3.2. Pabellón auxiliar y Túnel de conexión

Es de planta rectangular y cubierta plana, estructuralmente no presenta ninguna característica especialmente reseñable. La fachada principal, esta formada por un sándwich de 

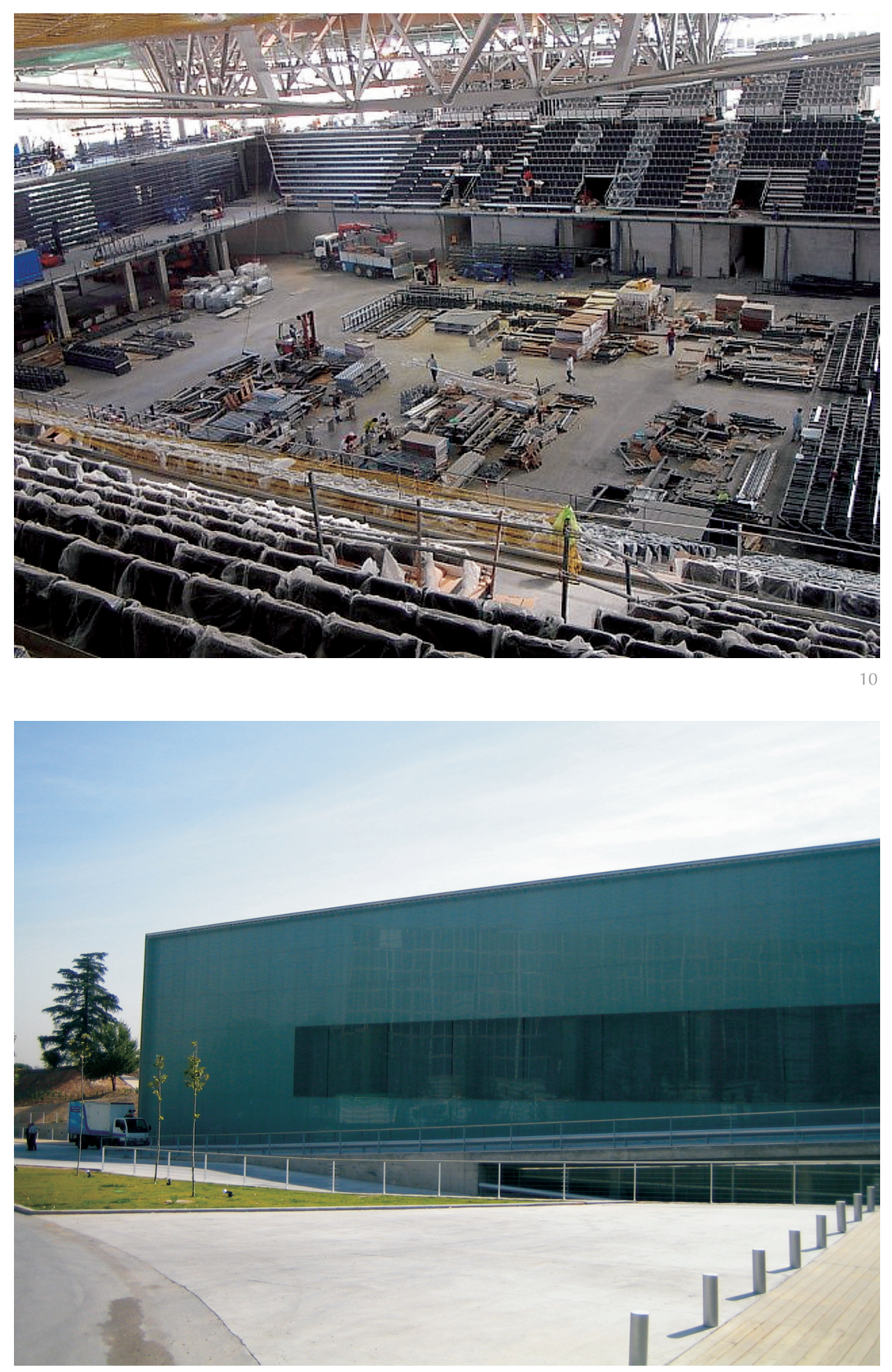

aproximadamente $1.50 \mathrm{~m}$ de espesor compuesto, desde el interior, por los siguientes elementos: panel VIROC móvil, fachada de metacrilato y malla de acero inoxidable tensada (Figura 11).

El resto de las fachadas están forradas exteriormente por paneles de zinc de acabado natural. La Cubierta, está formada por paneles de zinc de acabado natural. Los Acabados interiores, tanto en el Pabellón auxiliar como en el Túnel de conexión poseen el mismo carácter de nobleza. Los del PabeIlón están compuestos por tablero VIROC perforado y liso en acabado bruto, largos pasillos de vidrio con puertas correderas también realizadas de metacrilato y baños con revestimiento interior de paneles fenólicos. Los del Túnel de conexión se han realizado con chapa grecada y muros enteros revestidos por paneles retroiluminados de vidrio extraclaro.
10. Montaje de las gradas retráctiles.

11. Fachada del pabellón auxiliar. 


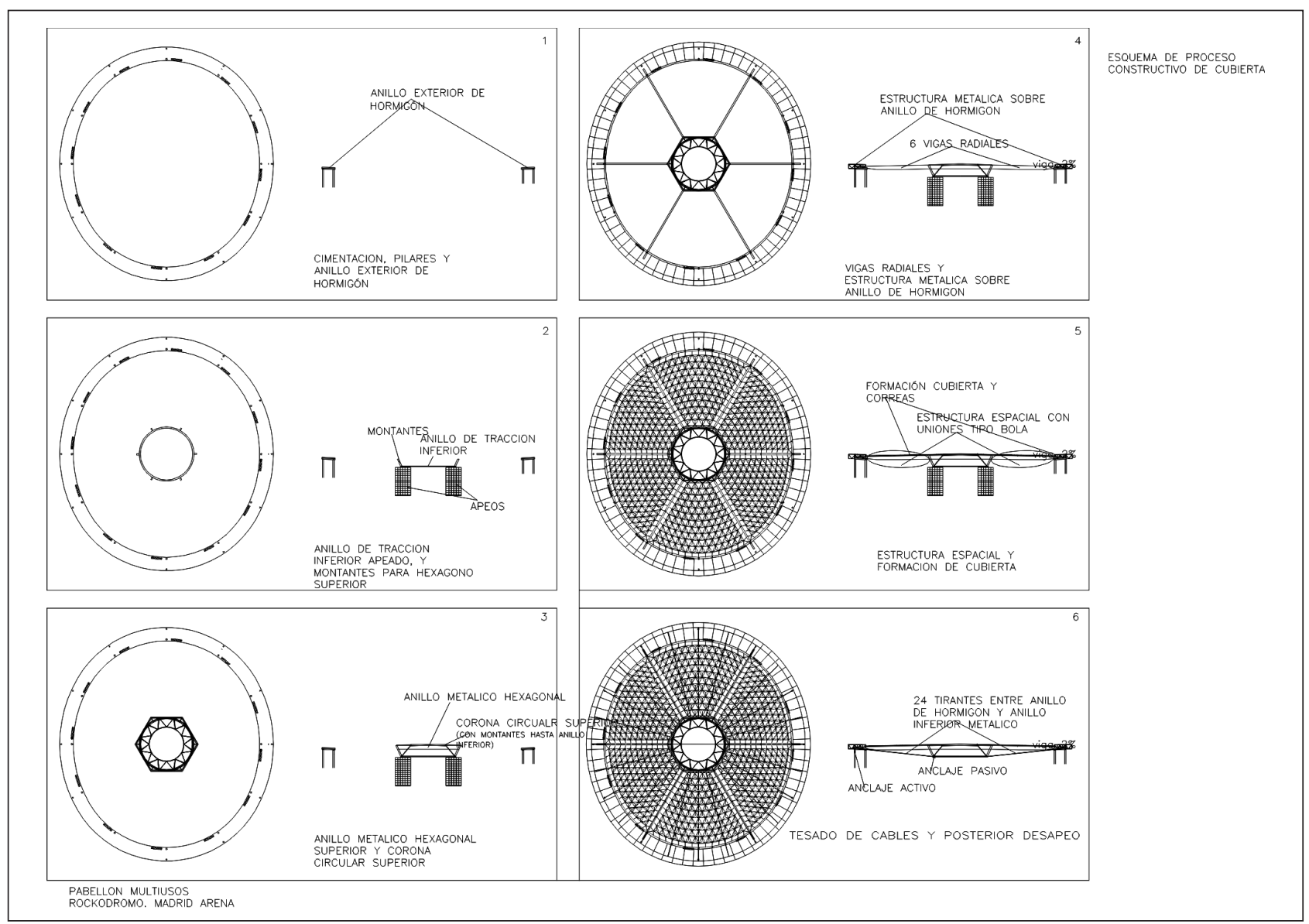

12. Esquema del proceso constructivo de la cubierta.

\section{INSTALACIONES}

\subsection{Pabellón Arena}

Las instalaciones con las que está dotado el pabellón son las siguientes:

Eléctrica, comprende una potencia instalada de 6.000 KVA en transformación de la red eléctrica, de la cual 2.000 KVA son de reserva para futuros usos. Existen además 3.000 en potencia auxiliar generada por grupos electrógenos.

Climatización, comprende cinco plantas enfriadoras que suministran una potencia de frío instalada de $5.750 \mathrm{KW}$ y cuatro calderas que suministran $3.870 \mathrm{KW}$ en calor, distribuidas en cuatro tubos a 6 climatizadores en el recinto principal, 9 secundarios en vestíbulos y 42 fan-coils. Accesos, comprenden 4 ascensores y 4 escaleras eléctricas.

Además cuenta con instalaciones de megafonía y telecomunicaciones, fontanería con distribución de agua fría y caliente para aseos, e instalaciones de detección y extinción de incendios.

\subsection{Pabellón auxiliar y Túnel de conexión}

Las instalaciones con las que están dotados estos dos edificios son:
Eléctrica, comprende una potencia instalada de $6.000 \mathrm{KVA}$ en transformación de la red eléctrica, de la cual 2.000 KVA son de reserva para futuros usos. Existen además 3.000 en potencia auxiliar generada por grupos electrógenos. Climatización, comprende cinco plantas enfriadoras que suministran una potencia de frío instalada de $4.940 \mathrm{KW}$ y cuatro calderas que suministran $3.645 \mathrm{KW}$ en calor, distribuidas en cuatro tubos a 6 climatizadores en el Pabellón auxiliar y 1 en el Túnel de conexión. Accesos, 1 ascensor.

Además cuenta con instalaciones de megafonía y telecomunicaciones, fontanería con distribución de agua fría y caliente para aseos, e instalaciones de detección y extinción de incendios.

\section{PROCESO CONSTRUCTIVO}

La ejecución del proyecto supuso una serie de subprocesos constructivos, de los cuales los más característicos son los cinco que se describen a continuación y que se contemplan en el esquema de la Figura 12.

\subsection{Tesado de la cubierta}

La sustentación de la cubierta esta formada por una estructura metálica apoyada en un anillo de hormigón y un sistema pretensado 

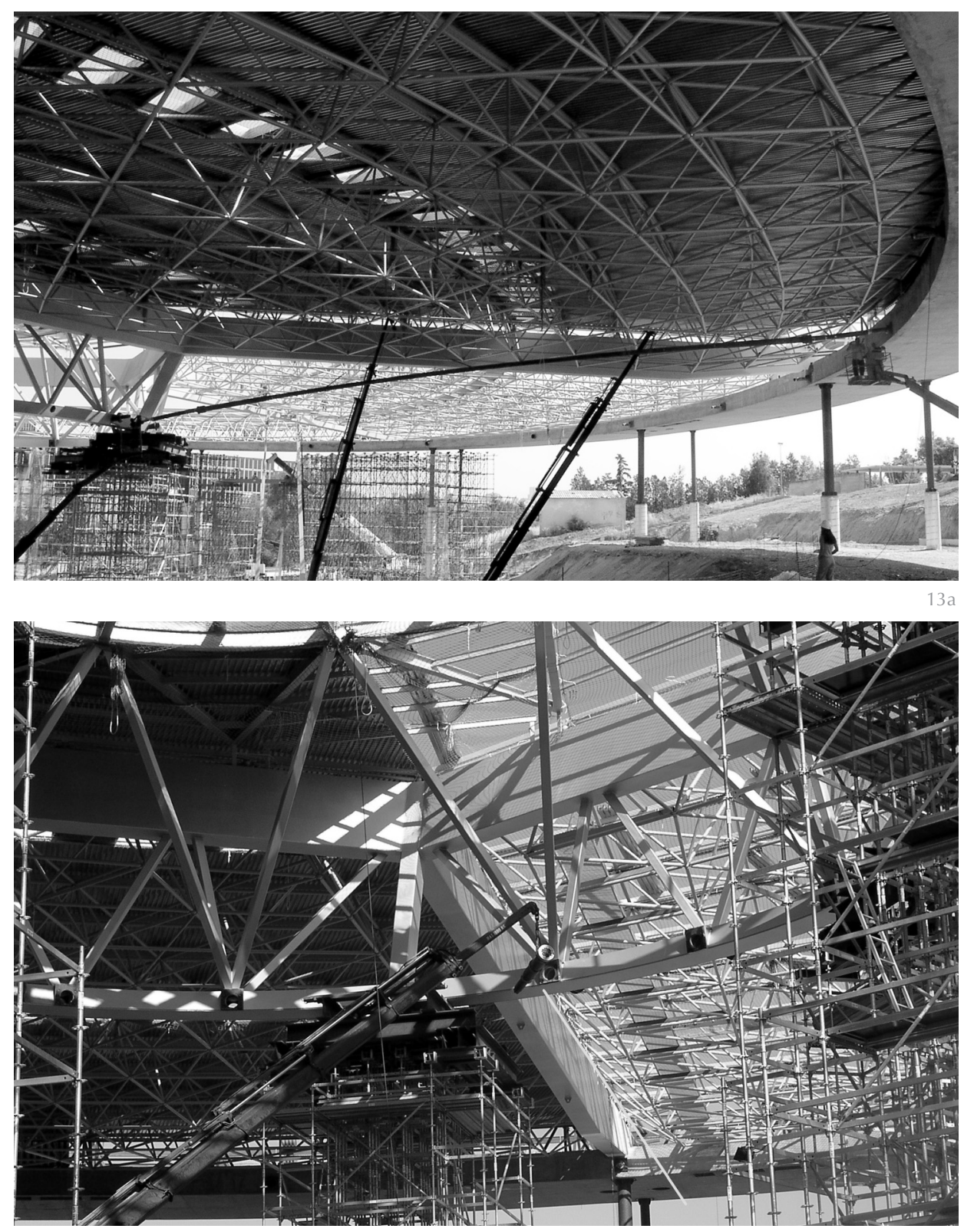

exterior que une el anillo con una corona, anillo inferior, que forma parte de la estructura metálica.

Como se ha comentado anteriormente el fundamento estructural de la cubierta se parece al de una rueda de bicicleta, donde los tirantes de pretensado hacen de radios y absorben las tracciones

El sistema de pretensado incluye 24 anclajes pasivos situados en la corona metálica y 24 anclajes activos en el anillo de hormigón. Entre cada pareja de anclajes hay una vaina de PEAD recubierta de otra de acero que contiene 31 cables de 0.6".

Previamente al tesado se dejaron embebidos los 24 anclajes metálicos en el anillo exterior antes del hormigonado, y se procedió a la ejecución de 24 cabezas de anclaje en la corona interior metálica fabricadas en taller. A continuación se elevaron, utilizando camiones grúa, las vainas que van de la cara interior del anillo de hormigón a la exterior metálica, Figura 13a. En cada vaina se introdujeron los 31 cordones de 0.6 "para a continuación colocar las placas de anclaje, Figura 13b.

En todas las fases se tesaron simultáneamente los tirantes diametralmente opuestos para evitar desequilibrios importantes en la estructura, realizándose el control del tesado mediante manómetros calibrados.

El subproceso de tesado de tirantes se desarrolló de la siguiente manera (ver Figura 14, pág. siguiente):

1. Tesado unifilar, cable por cable, de cada uno de los 31 cordones que componen cada tirante hasta una fuerza final por tirante de $75 \mathrm{TM}$. 

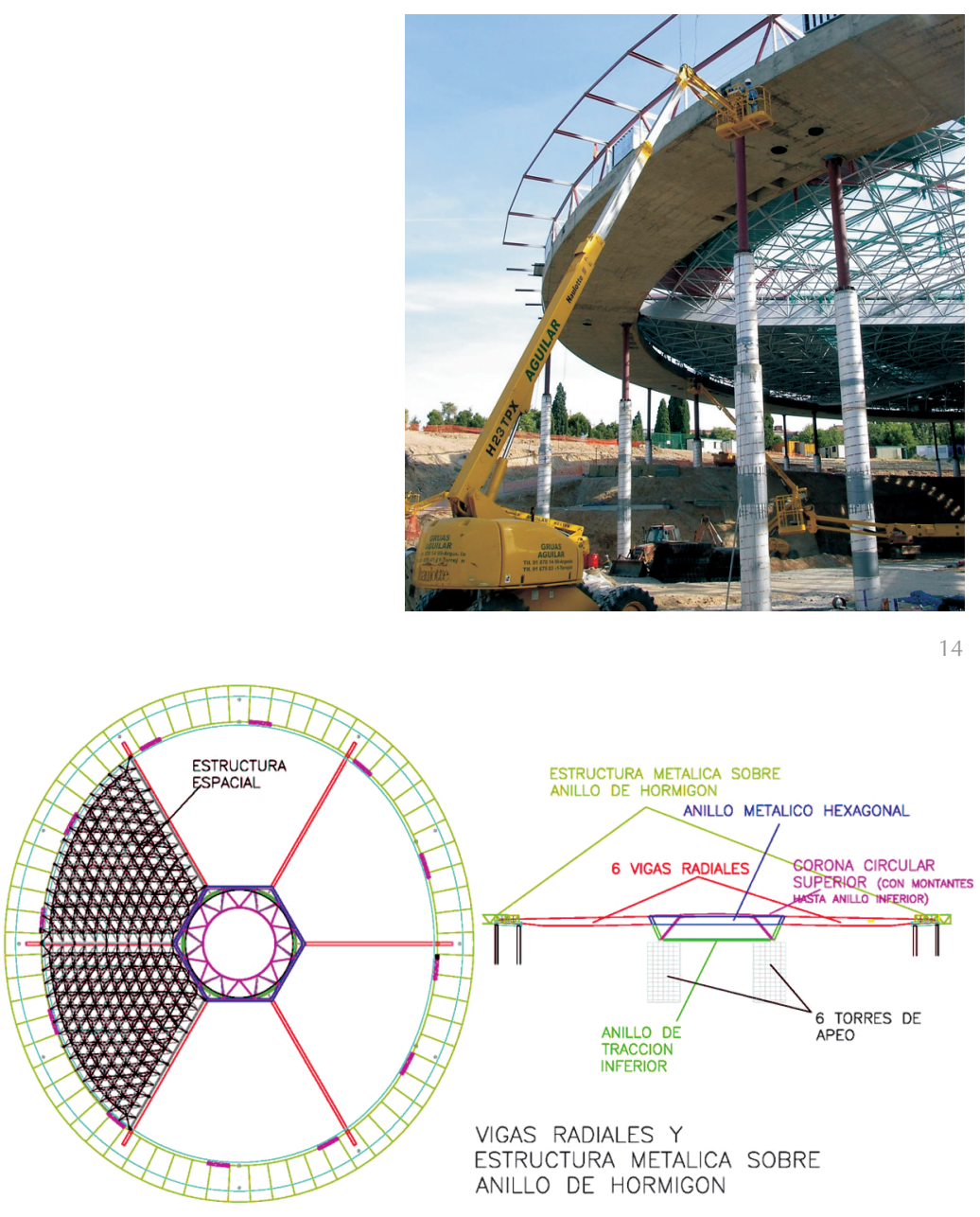

ANILLO DE HORMIGON

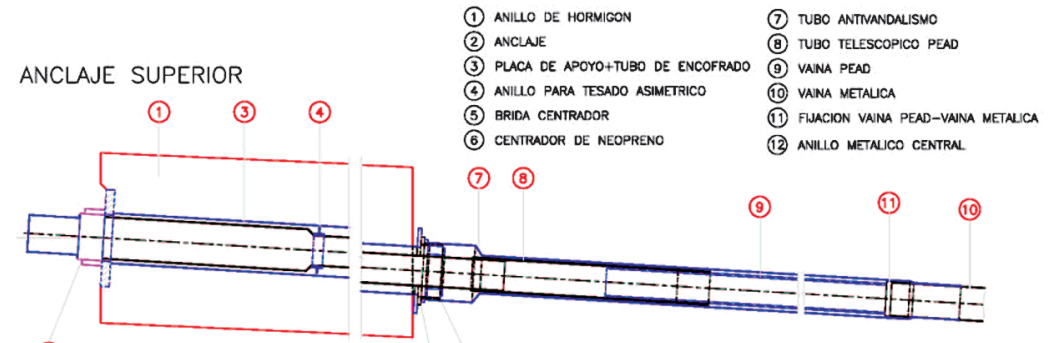

(2)

(5) (6)

(11)

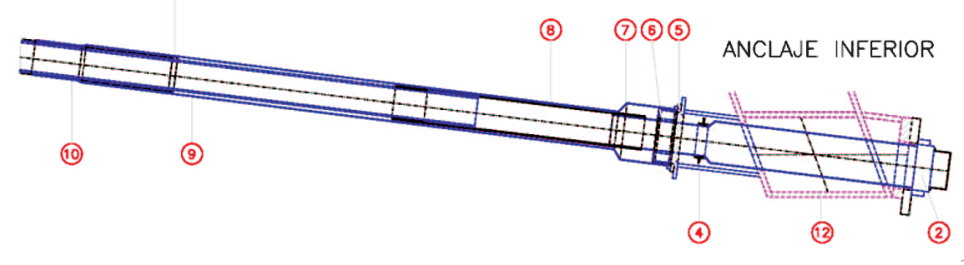

14. Tesado en distintas fases desde anclaje activo en anillo de hormigón exterior.

15. Composición de la estructura metálica.

\subsection{Desapeo de estructura metálica}

La estructura metálica está compuesta por un hexágono central superior formado por chapas armadas de $16 \mathrm{~m}$ de lado, un anillo central inferior compuesto de chapas armadas de $16 \mathrm{~m}$ de radio, unos montantes formados por chapas armadas y perfiles rectangulares que unen el hexágono superior con el anillo inferior y 6 vigas armadas que unen el hexágono superior con el anillo exterior de hormigón armado, Figura 15

Para el montaje de la estructura metálica fue necesaria la colocación de unas torres de apeos provisionales, necesarias hasta que los tirantes que unían el anillo de hormigón con el anillo metálico inferior fueran tesados, Figura 16. Una vez que el pretensado exterior entró en carga, la estructura pudo ser desapeada.

Este subproceso se desarrolló de la siguiente manera:

1. Se apeó toda la estructura metálica sobre 6 torres de apeo o cimbras del tipo PERI-U.

2. Tras el tesado de los cables de los tirantes, estos pasaron a transmitir gran parte de la carga, inicialmente apoyada en las torres de apeo a los pilares y al anillo de hormigón. El resto de la carga, un pequeño porcentaje del total, permanecía sobre las cimbras a la espera del desapeo y que con el descenso esperado, sería transmitida a los tirantes y a su vez soportada por los pilares.

3. Sobre cuatro de las 6 torres de apeo se colocaron, por cada torre, 2 gatos, calzos y estructura auxiliar de desapeo. Quedando las dos torres correspondientes al diámetro del menor óvalo de hormigón sin estructura de desapeo.

4. A continuación se procedió a cargar los 8 gatos, 2 por cada torre, y ascender la estructura $2 \mathrm{~cm}$, quedando las dos torres anteriormente mencionadas sin carga y pudiéndose proceder a su desmontaje. Repitiendo periódicamente esta maniobra se logró descender el conjunto anillo hasta un máximo de 320 $\mathrm{mm}$. Todo el conjunto de maniobra fue coordinado por una central hidráulica para que los 8 gatos trabajasen conjuntamente y no hubiera descensos asimétricos. El sistema constaba de indicadores de capacidad de carga de los gatos y carrera de los mismos. En el caso de que los $320 \mathrm{~mm}$ de holgura de que disponían las torres no hubiesen sido suficientes, se hubiera procedido a otra operación de desapeo con una nueva estructura auxiliar.

5. Una vez las cimbras quedaron liberadas y la carga de la estructura metálica fue ab- 
sorbida por los tirantes y pilares, se procedió al desmontaje de las estructuras auxiliares de desapeo y posteriormente de las torres, Figuras 17, 18.

Los valores reales de descenso coincidieron con los cálculos previstos. El tiempo de la maniobra fue de seis horas.

\subsection{Descenso de encepados}

Debido a la modificación del proyecto mencionada anteriormente, se presentó el problema de que dos de los encepados quedaban a una altura intermedia en una de las zonas de accesos principales. Para solucionar este problema se pensó en cortar estos encepados y descenderlos hasta una posición en que no perturbaran la funcionalidad del edificio.

Este subproceso se desarrolló de la siguiente manera:

1. Ejecución de micropilotes provisionales desde la cota actual del terreno $(620,50)$, para durante el proceso de eliminación y creación del nuevo encepado sujetar los pilares que sirven de apoyo.

2. Excavación hasta la cota superior del encepado definitivo $(618,00)$

3. Excavación de los encepados de micropilotes, colocación de las tapas de estos y ejecución de los encepados.

4. Ejecución de la estructura metálica de los pórticos pasivos apoyados sobre los encepados de los pilotes.

5. Colocación de las coronas metálicas de transferencia y conexión de las mismas a los soportes.

6. Arrostramiento en la cabeza de los soportes al anillo mediante un sistema de apretadura de barras DYWIDAG a través de los alvéolos existentes en el anillo de hormigón de la cubierta.

7. Disposición de los mecanismos de control de movimientos mediante nivel de precisión con objeto de contrastar cualquier incidencia a partir de la excavación del terreno hasta la cota definitiva $(616,00)$.

8. Excavación hasta la cota definitiva dejando los micropilotes descubiertos en la zona de encepado sobre pilote único de diámetro 1,50 .

9. Corte mediante hilo de diamante refrigerado y demolición de la parte del encepado correspondiente al pilote de 1,50 de diámetro y eliminación de los $10 \mathrm{~cm}$ exteriores del

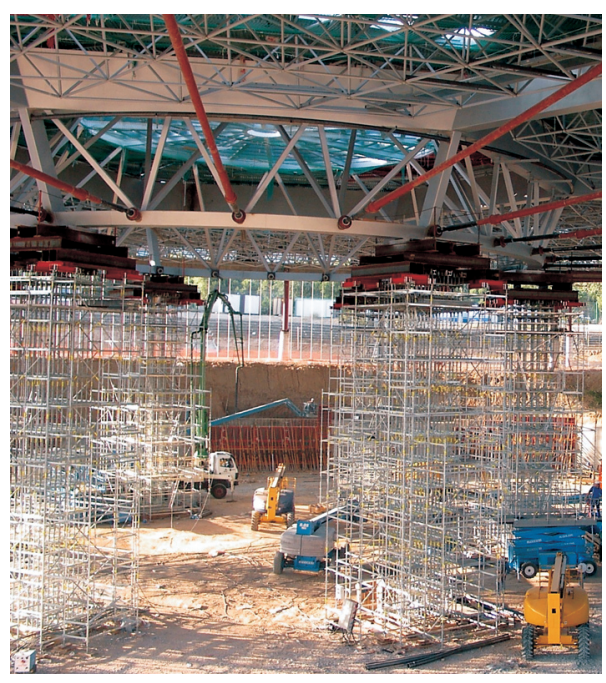

16

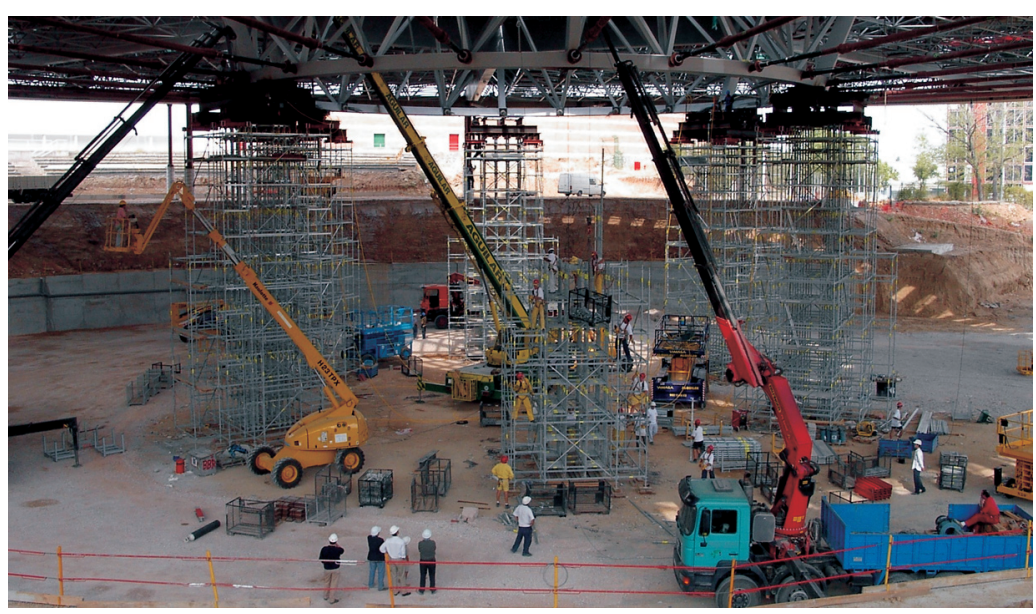

17

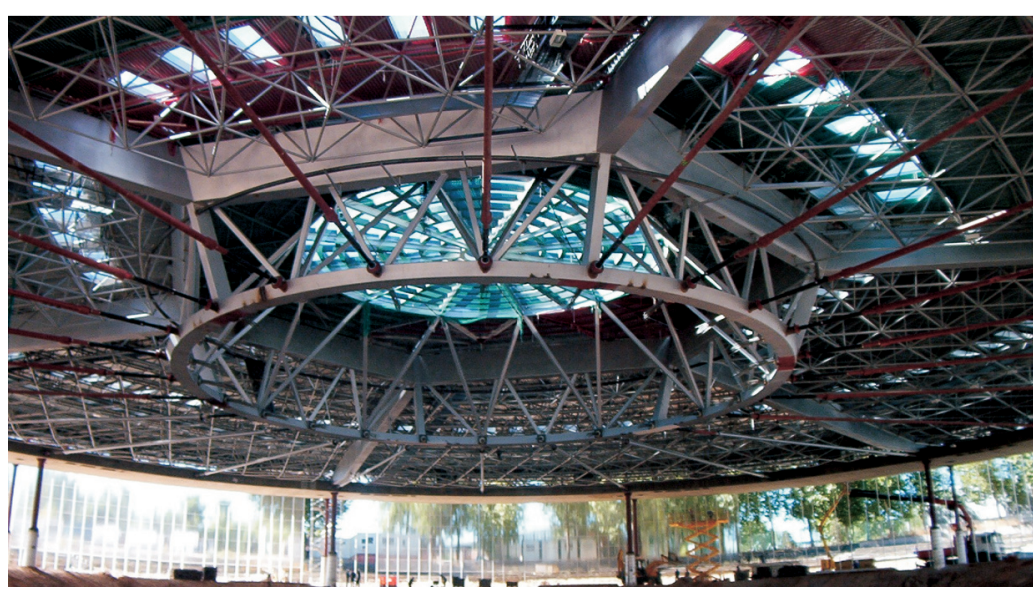

propio pilote hasta alcanzar la cota definitiva $(616,00)$.

10. Limpieza de materiales y ejecución del armado tanto de la zona de encepado sin eliminar como del pilote.

16. Estado previo al desapeo.

17. Desmontaje de torres tras el desapeo.

18. Aspecto de la cubierta tras el desmontaje de torres.

11. Disposición de las armaduras del encepado que incluye además atado con las zonas bajo los encepados de micropilotes, conexión 
con el resto del encepado correspondiente a la pila aún sin tratar.

12. Hormigonado del nuevo encepado bajo el fuste en ejecución dejando las armaduras salientes para conexión con el nuevo fuste de hormigón hasta una altura de 1,50 m sobre la cara superior del nuevo encepado.

13. Colocación de armaduras del nuevo pilar en el tramo coincidente con el antiguo encepado y pilote en la zona que rodea al picado.

14. Hormigonado y colocación del manguito superior en el armado para dar continuidad del soporte hasta la cota 623,30.

15. Colocación de armadura y hormigonado de la pila definitiva.

16. Excavación hasta cota 617,55 en la zona de encepado sobre los pilotes de 0,85 de diámetro.

\section{Picado selectivo de pilotes.}

18. Colocación de armaduras de encepado en la zona de pilotes de 0,85 de diámetro en continuidad con la zona ya ejecutada. Colocación de armadura de la zona de continuidad soporte-encepado nuevo.

19. Hormigonado del encepado y de la zona de continuidad soporte-encepado.

20. Corte mediante lanza térmica y demolición de la parte restante del encepado antiguo, y eliminación de pilotes entre encepados.

21. Limpieza de materiales y ejecución del zunchado de la zona del encepado sin eliminar.

22. Colocación de armaduras del soporte en continuidad con la armadura del encepado y hormigonado del mismo.

23. Desmontaje de medios auxiliares.

\subsection{Ejecución de estructura prefabricada}

El subproceso constructivo de la estructura de hormigón prefabricada se desarrolló de la siguiente manera:

1. Replanteo, excavación, armado de la zapata y colocación de las vainas de $5 \mathrm{~cm}$ de diámetro antes del hormigonado para posteriormente introducir las esperas de los pilares.

2. Hormigonado de la zapata.
3. Inserción de las esperas de los pilares en las vainas y aplomado de los pilares.

4. Fabricación de encofrado para rellenar con mortero SIKA GROUT, mortero monocomponente, fluido, de resistencias mecánicas muy elevadas y rápido desarrollo, con excelente adherencia al hormigón y al acero.

5. Relleno de vainas y base de pilar con el mortero SIKA GROUT.

6. Una vez fraguado el mortero se procedió al acopio de las vigas prefabricadas en la base de los pilares para una colocación más rápida y efectiva. El apoyo de las vigas prefabricadas se resolvió en esta obra de tres formas distintas:

a. Apoyo en los pilares prefabricados.

b. Apoyo en muro y pilar prefabricada. A la vez que se realizó el muro se encofraron unos cajones de madera para el posterior apoyo de las vigas de hormigón prefabricado.

c. Apoyo en pilar prefabricado y placa metálica sobre placas de neopreno para el correcto funcionamiento de la estructura.

7. Una vez colocadas todas las vigas de un mismo sector se procedió a la colocación simplemente apoyada de las losas alveolares. En cada viga se apoyaron dos losas dejando un hueco en medio de al menos $10 \mathrm{~cm}$ que se rellenó posteriormente al realizar la capa de compresión.

8. Armado de las uniones sobre las vigas con redondos de del 12 .

9. Colocación del mallazo.

10. Hormigonado de capa de compresión.

11. Como complemento a esta estructura prefabricada se realizó un vuelo de menor canto que el forjado para poder albergar bajo él el sistema de graderío retráctil.

12. El voladizo se ejecutó con una prelosa, también de hormigón armado acabada en su parte frontal con un tubo de acero estructural y una tabica de metálica

En la Figura 19 se puede ver el aspecto general de la estructura prefabricada.

\subsection{Ejecución de fachada del Pabellón Principal}

Como se mencionó anteriormente, la fachada de $350 \mathrm{~m}$ de perímetro y $9 \mathrm{~m}$ de altura, esta realizada en muro cortina compuesto por dos capas independientes, sistema ya utilizado en repetidas ocasiones en edificios de esta entidad, de vidrio STADIP extraclaro 
de espesores $8+8$ y $10+10$ sustentadas en su interior por cerchas metálicas apoyadas en el forjado del nivel $+11,00$ y soldadas a unas ménsulas que sobresalen del anillo superior de hormigón. Su ejecución planteó una serie de problemas, uno de los cuales se refiere a los huecos realizados en el forjado para su posterior uso como ventilación de una galería de instalaciones situada en la parte posterior.

Este subproceso constructivo se desarrolló de la siguiente manera:

1. Replanteo, y colocación en el anillo superior de hormigón de placas. Debido a que el ovoide que representa el perímetro exterior del Madrid Arena es una curva de cuarto orden, el replanteo de dichas placas debió ser preciso. Cada una de ellas se replanteó con el topógrafo y con la ayuda de una carretilla elevadora.

2. Soldado de ménsulas formadas por perfiles de tubo estructural de 120x80/6.

3. Aplomado y posterior calzado de las cerchas. La fabricación de dichas cerchas se realizó en taller siendo supervisadas mediante distintas visitas de jefatura de obra.

4. Colocación de perfiles de acero LD para arriostrar las cerchas entre ellas, y para posterior colocación de pasarelas de vidrio a distintas alturas.

5. Colocación de luminarias en los 4 niveles de pasarela en el interior del muro cortina, a 2,$5 ; 4,5 ; 6,5$ y 9 m del suelo.

6. Colocación de escaleras de pates de comunicación entre las distintas alturas del muro cortina.

7. Colocación de la estructura horizontal de la carpintería del muro cortina formada por perfiles de aluminio.

8. Colocación, con ayuda de plataformas elevadoras, de los vidrios de dimensiones aproximadas $2.00 \times 4.00 \mathrm{~m}$ y $2.50 \times 4.00 \mathrm{~m}$.

\section{Sellado de los vidrios.}

10. Colocación de los vidrios interiores de las pasarelas, tipo STADIP de dimensiones $4+4$ y $5+5$ translúcidos.

11. Al final de la ejecución del muro cortina, se procedió a la colocación de las puertas, compuestas por perfiles de tubo estructural y forradas de vidrio en sus dos caras con

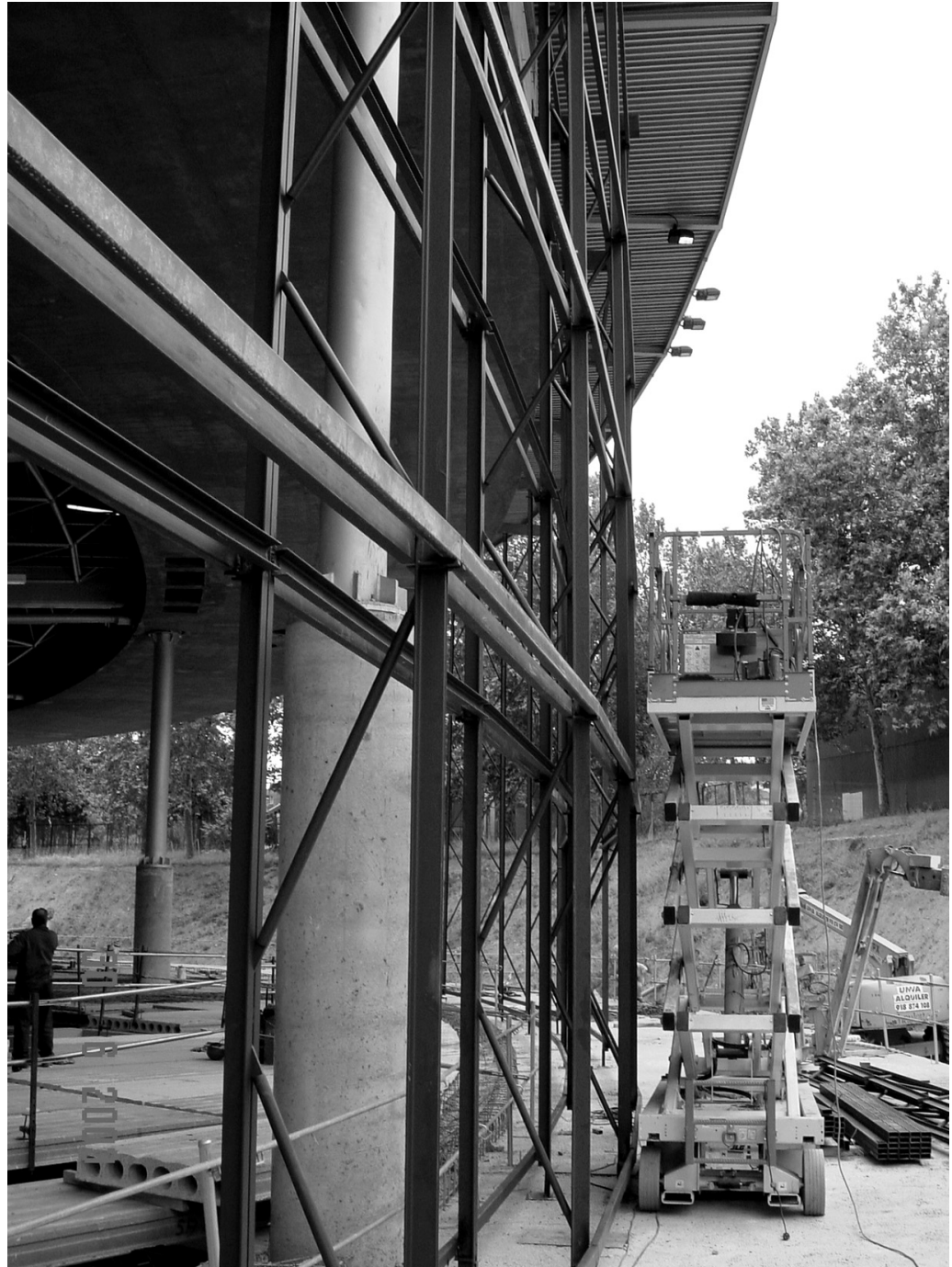

19

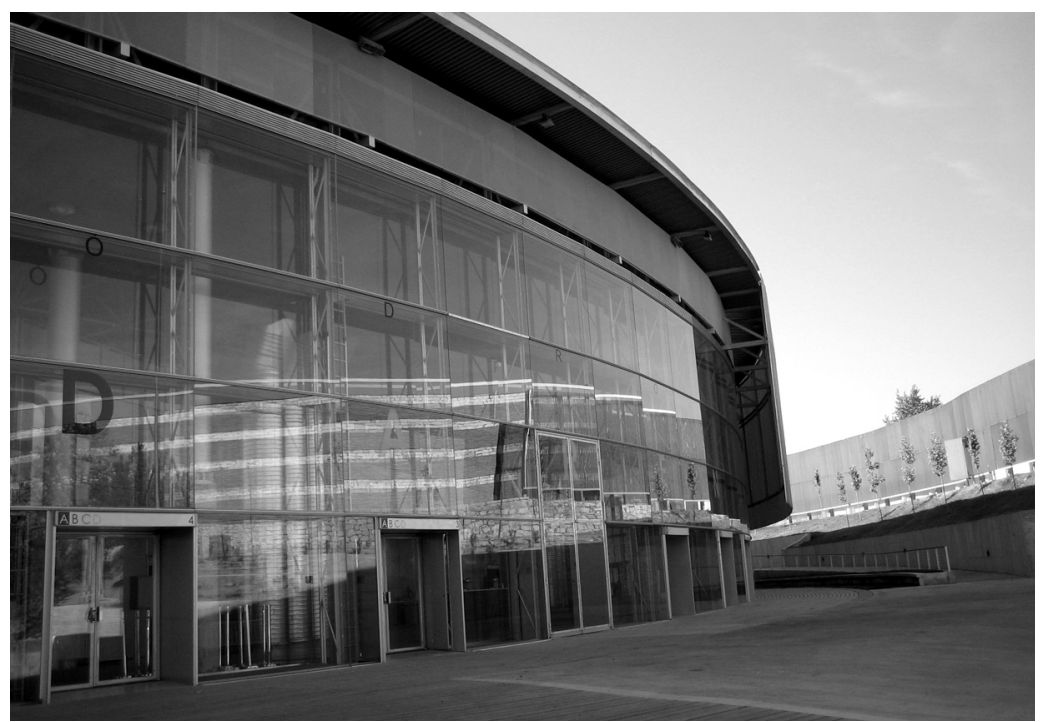

cerraduras antipánico de la marca D’LINE. En la Figura 20 se puede ver el aspecto de la fachada terminada
19. Aspecto general de la estructura prefabricada.

20. Aspecto de la fachada termi- 


\section{FICHA TÉCNICA}

\section{DATOS DE OBRA}

\begin{tabular}{|c|c|c|c|}
\hline & \multicolumn{2}{|c|}{ FASE I } & FASE II \\
\hline OBRA ( $n^{\circ}$ SIE) & $\begin{array}{l}\text { PC2 ESTRUCTURA } \\
\text { Y CUBIERTA } \\
\text { ROCKÓDROMO } \\
(155-176)\end{array}$ & $\begin{array}{l}\text { PC3 Y PC4 } \\
\text { URBANIZACIÓN, } \\
\text { ACABADOS E } \\
\text { INSTALACIONES } \\
\text { ROCKÓDROMO } \\
(155-177)\end{array}$ & UTE ROCKÓDROMO $2^{\mathrm{a}}$ Y $3^{\mathrm{a}}$ FASE (155-185) \\
\hline ORGANIZACIÓN & FCC (100\%) & $\begin{array}{l}\text { UTE FCC }(45 \%) \\
\text { ACS }(45 \%) \\
\text { ORTIZ }(10 \%)\end{array}$ & UTE FCC (40\%), ACS (40\%), ORTIZ (20\%) \\
\hline COMIENZO-FIN DE OBRAS & MAY 02 -ОСТ 02 & JUL $02-0 C T 02$ & FEB 03 - ОСТ 05 \\
\hline PROPIEDAD & \multicolumn{3}{|c|}{ EMPRESA MUNICIPAL CAMPO DE LAS NACIONES } \\
\hline DIRECCIÓN PROYECTO & $\begin{array}{r}\text { DÑA. SARA DE LA } \\
\text { ESTUDIO CANO }\end{array}$ & $\begin{array}{l}\text { MATA (GMU) } \\
\text { ASO }\end{array}$ & $\begin{array}{l}\text { DÑA. SALA DE LA MATA / DÑA. PALOMA HUIDOBRO } \\
\text { ESTUDIO CANO LASO }\end{array}$ \\
\hline DIRECCIÓN OBRA & \multicolumn{3}{|c|}{ D. ENRIQUE RAMÍREZ (GMU) / D. JAVIER MARTíNEZ } \\
\hline $\begin{array}{l}\text { PROYECTO Y DIRECCIÓN } \\
\text { ARQUITECTURA }\end{array}$ & \multicolumn{3}{|c|}{ ESTUDIO CANO LASO } \\
\hline PROYECTO ESTRUCTURA & \multicolumn{3}{|c|}{ MC2 - D. JULIO MARTÍNEZ CALZÓN } \\
\hline $\begin{array}{l}\text { PRYTO. Y DIRECC. } \\
\text { INSTALACIONES Y } \\
\text { CONTROL EJECUCIÓN }\end{array}$ & \multicolumn{3}{|l|}{ TYPSA } \\
\hline
\end{tabular}

EQUIPOS DE OBRA DE FCC

\begin{tabular}{|c|c|c|}
\hline & FASE I & FASE II \\
\hline $\begin{array}{l}\text { GERENTE- } \\
\text { JEFE DE DEPARTAMENTO }\end{array}$ & \multicolumn{2}{|c|}{ D. FRANCISCO JAVIER CORDOBA } \\
\hline JEFES DE OBRA & D. FRANCISCO J. PELLUZ & $\begin{array}{l}\text { D. FRANCISCO J. PELLUZZ } \\
\text { D. ENRIQUE DÍAZ }\end{array}$ \\
\hline JEFES DE PRODUCCIÓN & $\begin{array}{l}\text { D. JUAN MANUEL TORRES } \\
\text { D. DAVID ALVAREZ }\end{array}$ & $\begin{array}{l}\text { DÑA. MARGARITA SANCHEZ } \\
\text { D. JUAN MANUEL TORRES } \\
\text { D. RAFAEL FOULQUIÉ }\end{array}$ \\
\hline ADMINISTRATIVOS & $\begin{array}{l}\text { D. VÍCTOR COLLAR } \\
\text { DÑA LAURA ROMERO }\end{array}$ & DÑA. BEATRIZ SOBLECHERO \\
\hline ENCARGADOS & $\begin{array}{l}\text { D. OLIMPO TORRES } \\
\text { D. MANUEL ESCRIBANO }\end{array}$ & $\begin{array}{l}\text { D. OLIMPO TORRES } \\
\text { D. MANUEL ESCRIBANO } \\
\text { D. PASCUAL BERMEJO }\end{array}$ \\
\hline ASESORIA ESTRUCTURAS & $\begin{array}{l}\text { DIRECCIÓN SIST. ESPECIALES } \\
\text { D. LUIS VIÑUELA } \\
\text { D. JOSÉ MARTÍNEZ SALCEDO }\end{array}$ & \\
\hline
\end{tabular}

